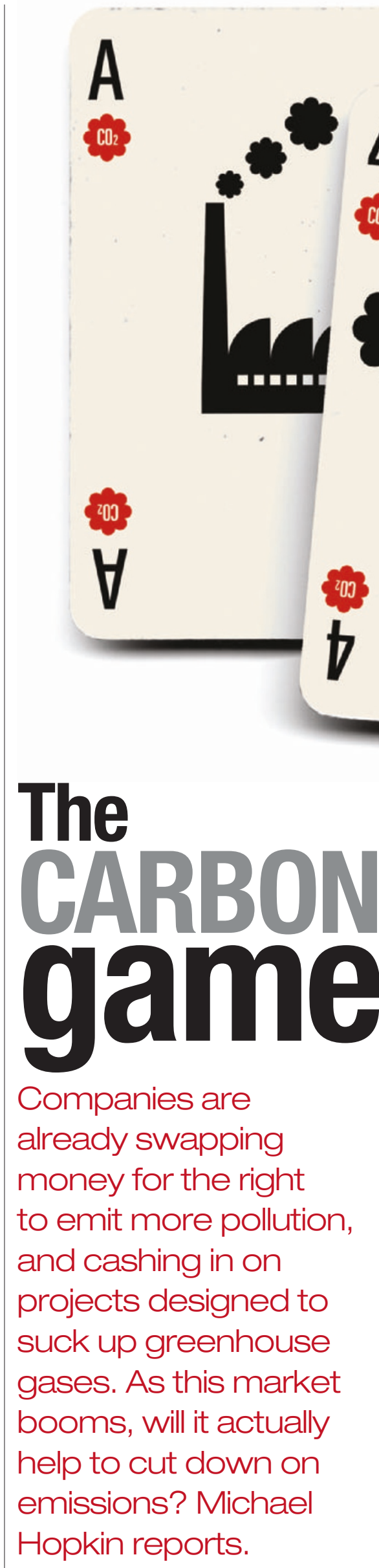

T his summer, a group of power companies in Japan and Canada developed an unusual interest in pig manure. The porcine waste was at the heart of a landmark multimillion-dollar deal between Chile's largest pork producer and the power companies, allowing the latter to emit more pollution. The pig farm promised to recycle its animals' emissions of methane - a potent greenhouse gas - by covering the manure, capturing the gas, and burning it as sustainable energy. In return, the power companies bought the right to emit more carbon dioxide from their stations, half a world away from the oblivious pigs.

The deal, signed in August, is one of the largest such exchanges, but it is by no means the first: trading in greenhouse-gas emissions has been going on since the mid 1990s. That may seem strange in a world that has not yet entered into the full grip of the Kyoto Protocol - the international agreement that aims to reduce greenhouse-gas levels, in part by allowing companies to buy and sell'equivalents' of carbon dioxide emissions. But, as the ink is drying on that deal thanks to Russia's recent ratification of the treaty (see Nature 431, 1030; 2004), carbon markets are already doing brisk business.

Carbon trading has been slowly growing since its inception (see Graph, opposite), and is now set to explode under the stewardship of a handful of dedicated brokers. By the end of this year, the total volume of $\mathrm{CO}_{2}$ traded is expected to be double that of 2003. But 2005 will be the year in which the trade truly comes of age, when in January the European Union (EU) launches its Emissions Trading Scheme (ETS), involving some 12,700 industrial organizations spread across all $25 \mathrm{EU}$ member states. By 2007, the European market is expected to be worth $€ 10$ billion (US\$13 billion) per year, says Henrik Hasselknippe, an analyst at consultancy firm Point Carbon in Oslo, Norway.

\section{Trading places}

Emissions limits in the ETS are established by National Allocation Plans - proposals submitted by each EU member state that are now being individually approved by the European Commission. Once they get the green light, governments farm out their allowances to industrial installations such as power companies, mineral miners, and cement and paper manufacturers giving each an allotment of 'emissions credits' that they can trade internationally. The governments involved keep track of the emissions, based mainly on the known inputs to these installations, and update their figures with information on registered trades. For every tonne of $\mathrm{CO}_{2}$ emitted above the limit, companies face a fine of $€ 40$, rising to $€ 100$ from 2008 onwards.

In tandem with schemes designed to increase compliance with Kyoto - such as the ETS and forthcoming systems in Canada 
and Norway - companies also trade in emissions on their own, in part to showcase a certain amount of civil responsibility to their stock-holders. In the absence of official, nationally allocated 'carbon emission credits', they trade in projects instead — such as the pig-farm deal. Some trading even goes on in countries that have not ratified the Kyoto deal, such as the United States and Australia. And independent day-traders, who will use the market to make a quick buck rather than to manage emissions, are expected to arrive on the scene soon.

Carbon trading is seen by most as an economic necessity - one that might also benefit the environment. Turning emissions into a commodity gives companies a financial incentive to clean up their act by more than is legally required: a small, voluntary market set up in the 1990s in the United States seems to have proved that emissions fall when reductions are made valuable. But some researchers and politicians are sceptical that a global scheme will likewise reduce emissions, rather than simply shifting pollution around. The negotiations that set up national carbon allowances may have been over-generous, they say, the price of carbon credits may be too cheap, and the future reliability of plans to generate credits may be suspect.

\section{Gas exchange}

The idea of a carbon market was written into the Kyoto Protocol thanks mainly to pressure from the United States, which nevertheless pulled out of the treaty in 2001. The idea was that many countries would agree to long-term emission reductions only if companies were allowed to buy the right to more emissions when needed. Such a trading scheme would spread the burden of emissions costs to those most able to support them. This has been shown to work in other contexts, primarily the US scheme for trading sulphur dioxide emissions, which is widely regarded as a triumph of market forces enforcing environmental rules.

The US scheme, known as the Acid Rain Program, was a drive to cut emissions from coal-burning power stations in response to a 1990 tightening of the US Clean Air Act. The programme worked on a 'cap and trade' basis for $\mathrm{SO}_{2}$ : more than 260 of the most polluting power stations were given a maximum emissions allowance; anyone destined to exceed their limit had to buy extra credit from those who were ahead of the curve. By 2000, when the market was opened up to all US coal-fired power stations, $\mathrm{SO}_{2}$ emissions nationwide had fallen to about 11 million tonnes per year, down from almost 16 million tonnes in the late $1980 \mathrm{~s}^{1}$.

The ETS will attempt to pull off a similar trick for Europe's $\mathrm{CO}_{2}$ emissions. But with
25 countries all striving to cut emissions by dable proposition than the US scheme, which involved trading within a single industrial sector in a single country. "No one has ever done a trading scheme on this scale before," says Neil Strachan, an economist and climate researcher at the Pew Center on Global Climate Change in Arlington, Virginia.

Observers fervently hope that the ETS is a success - not just as an emissions-reducing measure but as a demonstration of Europe's traditional leadership in tackling climate change. If it works, it will set an example to the rest of the Kyoto countries, which in 2008 must begin fulfilling their own commitments.

Most trading in the ETS will fall into one of two categories: straight buying and selling of credit between members, and investment in the Clean Development Mechanism (CDM), a United Nations scheme to encourage the growth of environmentally friendly industry in the developing world.

The CDM has already thrown up some innovative ideas - the Chilean pigs again being an example. A handful of other strategies have also passed the UN's stringent verification process, which is designed to ensure that they deliver the carbon credit they promise. These include destroying the greenhouse gas HFC-23, a by-product in the manufacture of some chemical refrigerants, or converting the fumes from landfill sites into energy. But the most widely cited potential CDM method - planting forests of fastgrowing trees such as eucalyptus to soak up $\mathrm{CO}_{2}$ - has yet to be approved. Regulators have yet to be persuaded that schemes of this

Critics say the outcome of CDM projects that involve sequestration of $\mathrm{CO}_{2}$, rather than limiting emissions, can never be guaranteed. about $1 \%$ each year, it is a much more forminature are safe bets.

At the moment there are no accurate ways to predict the change in $\mathrm{CO}_{2}$ levels from such projects, or to verify that these changes actually take place. Even if there were, it would still leave other concerns. "What happens when you plant a eucalyptus forest, then there's a change of government and they chop it down and build a holiday resort?" asks Michael Dorsey, an environmental scientist at Dartmouth College in Hanover, New Hampshire. "Do you then destroy the power plant in America that got built because of the project?" Without carbon deficits as well as credits and without an effective way to penalize those who don't play by the rules - Dorsey argues it is nearly impossible to ensure that emissions will go down instead of up.

\section{In credit}

Others say that the entire CDM mechanism simply allows Western industry to keep developing while dropping stopgap solutions on the doorstep of the developing world. Although the projects may bring some industry and money to these nations, it isn't everyone who is benefiting. Currently, more than two-thirds of emissions reductions are supplied by just five countries: India, Brazil, Chile, Romania and Indonesia ${ }^{2}$. Most African countries have yet to broker a single deal. And once Russia enters the scene which it is expected to do soon - it should be able to earn billions from its emission quota, taking a large chunk of the market.

Russia is likely to have huge amounts of credit on its hands because Kyoto targets are based on emissions in the treaty's baseline year of 1990. Back then, smokestack industries of the old communist regime were still belching out masses of $\mathrm{CO}_{2}$. Since the collapse of the Soviet Union in 1991, Russia has shut these plants down, giving itself a surplus of allowable emissions that it can now sell on. Critics of carbon trading point out that if Russia sold all of its credits the consequences for emissions would be effectively the same

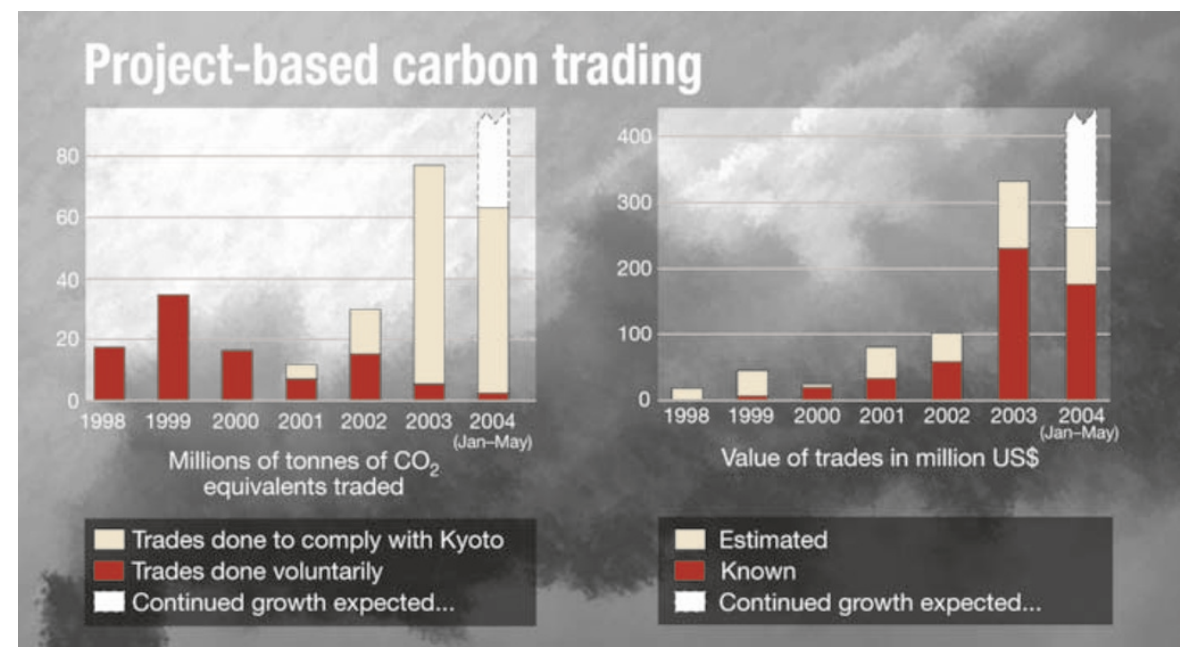

Growth industry: the trade in 'carbon credits' that buy companies the right to emit more pollution has increased steadily — by the end of this year, trade is expected to have doubled over 2003. 
as if someone cranked these old powerhouses back up to speed. In the short term that would be bad news for emissions, although the world would still be better off than it was 14 years ago.

Perhaps of greater concern are the emissions expected from other areas of industry that are exempt from the Kyoto Protocol and excluded from the carbon markets set up to help regulate it. Emissions from cars and planes, for example, are not included in national allocations. "The trading system covers only about $50 \%$ of total EU emissions - other sectors, such as transport, are still growing," says Hasselknippe.

\section{Fair price}

Despite these criticisms, the prevailing sentiment among marketeers and environmentalists is that emissions trading is the only pragmatic way forward, particularly considering how well it worked for $\mathrm{SO}_{2}$. After all, that market likewise faced complaints in its early years. "At the time we started $\mathrm{SO}_{2}$ trading we were called smogtraders and garbage-peddlers Greenpeace even picketed us," recalls says Richard Sandor, chief executive of the Chicago Climate Exchange, which was involved with the project. "But it has saved lives." He says that the \$1.2-billion cost of the scheme to the US economy has bought a \$27-billion reduction in the healthcare burden of lung disease through cuts in acid rain.

Sandor is now setting his sights firmly on a single worldwide carbon market, and has launched the European Climate Exchange, which will broker deals between members of the ETS. The move comes after the success of a voluntary carbon-trading scheme run by the Chicago exchange, also overseen by Sandor. This US market currently

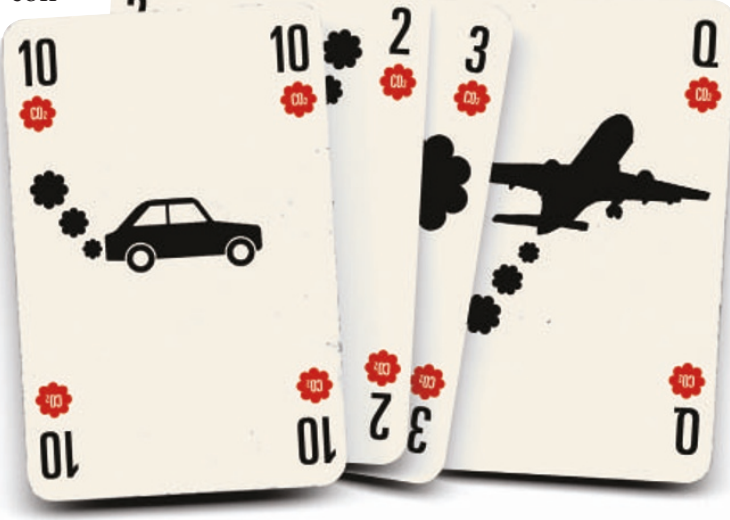

Bad hand: critics claim the carbon game can only succeed if it includes emissions from transport.

legislation that may appear in the future or rules that already exist. In Oregon, for example, power plants have an obligation to reduce emissions to $17 \%$ below that of the most efficient combined-cycle plants, or pay $\$ 0.85$ per tonne of excess emissions ${ }^{2}$.

Encouragingly, regulations in involves some 75 members drawn from the power, manufacturing, forestry and agriculture sectors, including names such as Ford, IBM, DuPont and Rolls-Royce. Together, they produce more emissions than the whole of Britain. Members signed a contract to reduce emis-
"We were called smog-traders and garbage-peddlers - Greenpeace even picketed us. But lives."

- Richard Sandor trading has saved

the voluntary Chicago scheme - which were determined by consulting businesses about what levels of reductions they would like to aim for - are surprisingly similar to regulations in the ETS, which were handed down from on high by the European government: both arrived sions by $1 \%$ a year, but Sandor claims that since trading began in December 2003, members' overall emissions have gone down by $9 \%$ - proof, say advocates, that the market works in favour of the environment.

The incentives for these US players are very different from those that relate to Kyoto. Some polluters may want to take action to avoid lawsuits such as those currently dogging the tobacco industry, says Sandor. Others may want to invest profitably in an environmentally friendly industry. Still others may want to steal a march on any at targets of $1 \%$ reduction a year. If industry self-assessment matches government enforcement, many argue, a workable worldwide market is a realistic possibility, regardless of different countries' motivations for playing the carbon game.

Once such a world market is established, it should, ideally, be self-regulating. The harder it is to comply with nationally enforced regulations, the higher the price of credits and the harder some companies will work to supply them.

At the moment, the price of a tonne of
$\mathrm{CO}_{2}$ credit in Europe is $€ 4-5$ for a CDM investment and $€ 8-9$ for a more straightforward trade of credits with another market member. Market observers say that these prices are quite low — slightly lower, for straight trades, than they were as recently as this February, thanks to relatively lenient caps given to many European companies by some national allocation plans. But the price could do anything once the market gets going, says Reena Qureshi of London-based co2e.com, which brokered the pig-farming deal. "It will respond to interest rates, or some analyst saying it's going to move, or political crises like the Iraq war," Qureshi says. Even the weather could sway the market - another heatwave like the scorching summer of 2003 would send power use skyrocketing, meaning that power companies could need to buy more emissions credit.

\section{Share and share alike}

Once it is officially launched, the European market will also be open to - and is expected to catch the attention of - independent day-traders hoping to make a quick buck. Suddenly the state of world emissions will become of intense interest to those who sit at their computers swapping stocks and shares. If nothing else, the market could then prove a positive exercise in increasing awareness of global warming.

Regardless of the price that credits reach, some observers say that it will always be too cheap compared with the true cost of pollution. "There's no mechanism for bringing prices into line with the social cost," says Melissa Carrington, a London-based analyst at consultancy firm PricewaterhouseCoopers. The fines $-€ 40$ per tonne for ETS members - will place a ceiling on market prices that many say is too low. One British government study puts the overall social cost of climate change to society - in terms of flooding, extreme weather and health issues - at about $€ 100$ per tonne of carbon emitted ${ }^{3}$.

Still, advocates point out, the market offers an economically viable strategy to get businesses on track towards emissions reduction: without carbon trading, the Kyoto Protocol would never have passed. As it is, the market puts companies in the right frame of mind, knowing that reductions equal cash. This in turn encourages power companies to manage their emissions and pig farms to recycle their manure - and surely that's a good thing.

\section{Michael Hopkin is a reporter for news@nature.com} based in London.

1. Ellerman, A. D., Joskow, P. L. \& Harrison, D. Emissions Trading in the US: Experience, Lessons and Considerations for Greenhouse Gases (Pew Center on Global Climate Change, Arlington, VA, 2003)

2. Lecocq, F. State and Trends of the Carbon Market 2004 (Carbon Finance at the World Bank, Washington DC, 2004).

3. Clarkson, R. \& Deyes, K. Estimating the Social Cost of Carbon Emissions Government Economic Service Working Paper 140 (HM Treasury, London, 2002). 